\title{
Effect of Liquid Acrylic Polymer on Geotechnical Properties of Fine-Grained Soils
}

\author{
Prabir K. Kolay ${ }^{1}$ - Basanta Dhakal ${ }^{1} \cdot$ Sanjeev Kumar ${ }^{1} \cdot$ Vijay K. Puri $^{1}$
}

Received: 13 July 2016/Accepted: 16 September 2016/Published online: 27 September 2016

(C) Springer International Publishing Switzerland 2016

\begin{abstract}
The present paper investigates the effect of liquid polymer on the geotechnical properties of fine-grained soil. Commercially available liquid polymer (acrylic polymer) was used to stabilize natural Carbondale soil (Soil A) and commercially available soil (Soil B). The polymer was mixed at various percentages (i.e., 2, 3, 4, and $5 \%$ ) of the dry weight of both soils. Tap water was added corresponding to its OMC (optimum moisture content) for a particular soil-polymer mixture and compacted to achieve its maximum dry unit weight. The compacted samples were allowed to cure for 7, 14, and 28 days under confined and open air environment. Unconfined compressive strength (UCS) test was performed to evaluate the strength of polymer stabilized soil. The results show that with the addition of polymer; UCS value for Soil B samples prepared at OMC increases from 30 to $75 \%$ in open air environment and the UCS value increases from 12 to $14 \%$ in confined air environment. Soil A samples prepared at OMC (i.e., $23.50 \%$ ) show cracks while curing in open air environment and there is no significant change (i.e., $1.2-13.8 \%$ ) of strength in confined air environment. For the Soil A samples prepared with reduced moisture contents (less than OMC i.e., $12.50 \%$ ) and cured in open air environment shows increase in UCS strength from 7 to $10 \%$. Also, California bearing ratio (CBR) test was performed for both soils and there was marginal increase (i.e., $14 \%$ ) in CBR value for Soil A but a significant increase (i.e., $340 \%$ ) in CBR value for Soil B.
\end{abstract}

Prabir K. Kolay

pkolay@siu.edu

1 Civil and Environmental Engineering Department, Southern Illinois University Carbondale, 1230 Lincoln Drive, MC 6603, Carbondale, IL 62901, USA
Keywords Fine-grained soils - Liquid polymer . Stabilization · Compaction · UCS · CBR

\section{Introduction}

Geotechnical engineers around the world have been using various method of soil improvement technique to solve the problem of non-availability of suitable material for construction. It is economical to improve the properties of existing soil rather than replacing the soil. Soil stabilization refers to the process to treat a soil to maintain, alter or improve the performance of the soil as a construction material and very important to reduce the cost of earthwork wherever good soil is not available nearby [1]. There are basically three ways to improve the soil: mechanical stabilization, chemical stabilization and physical stabilization [2]. Many traditional stabilizers like cement, lime, fly ash, bitumen etc., and many non-traditional stabilizers like polymer, enzymes, lignosulphates etc. have been used for soil improvement.

The use of non-traditional stabilizers, especially polymer, as an alternative to traditional stabilizers is increasing these days. The main advantage associated with non-traditional stabilizers is low cost, ease of application and less curing period. However, for non-traditional stabilizers due to their different chemical composition, very little is known about their interaction with the soil.

Generally, polymers are formed of long molecular chains (monomers) which are held together by covalent bonds [3]. Polymers may be natural or synthetic and are classified functionally as cationic, anionic and nonionic polymers. Polymers provide physical bonding between the soil particles rather than forming a new mineral by means of chemical reaction [4]. Onyejekwe and Ghataora [5] 
mentioned that, to get the full benefit from polymer stabilization one must identify the type of soil for which the polymer can be used. Sometimes the polymer might not work for a specific type of soil. It is also necessary to determine the application rate for particular type of soil. Also, polymer treated soil must loose moisture in order to gain strength, so the additives must be applied in dry weather conditions. It is necessary to adopt the suitable construction technique that considers the stabilization mechanism of the polymer. There are various types of polymers (e.g., acrylic copolymer and polymers, liquid polymers of methylacrylates and acrylates, copolymers of sodium acrylates and acrylamides, poly-acrylamide and copolymer of acrylamide (PAM), and hydro-colloid polymer) currently used for the purpose of soil stabilization [6].

Several researchers $[3,5,7-15]$ have used various types of polymer to stabilize different types of soil. The problem associated with polymer stabilizer is that they are sold with a commercial name and most of the times the manufacturer does not disclose the chemical composition of the polymer. This makes it difficult to characterize the performance of the polymer.

The main objective of this paper is to determine the effect of a liquid polymer, i.e., Acrylic polymer, on the geotechnical properties of two different types of finegrained soil. The liquid polymer is added at 2, 3, 4, and $5 \%$ by dry weight of the soil. Various physical and engineering property tests were performed on both the original soil and soil sample mixed with various percentages of liquid polymer to see the effect of polymer on fine-grained soil.

\section{Materials and Methods}

\section{Soil Types}

Two different types of soil were used for this study. Carbondale soil sample was collected near Carbondale wastewater plant, Carbondale, IL, USA, referred as 'Soil A'. Commercially available soil was supplied by Edgar minerals, FL, USA, referred as 'Soil B'. The Soil A sample was left to air dry and was grinded after drying. The grinded sample passes through US sieve \#40 was oven dried for $24 \mathrm{~h}$, and was placed in air tight container for further testing.

\section{Liquid Polymer}

The liquid polymer used in this study. The chemical name of the polymer is inorganic acrylic co-polymers. The polymer is anionic due to carboxylation. The physical and chemical properties of the polymer supplied by the manufacturer are given in Table 1.

\section{Testing and Characterization}

\section{Physical Properties Test}

Various laboratory tests were conducted to determine different physical properties and engineering properties of original and polymer stabilized soils. The physical property tests such as specific gravity, particle size analysis, Atterberg limits were performed. The engineering property tests like standard Proctor, unconfined compression, California bearing ratio were performed as per respective ASTM standards.

Specific gravity test was performed by using Ultrapyc 1200e manufactured by Quantachrome Instruments as per ASTM D5550-00 [16] standard. Oven dried Soil A and B were used to measure the specific gravity. Hydrometer tests were carried out to determine the particle size distribution for both Soil A and B using ASTM D422-63 [17] standard. The hydrometer type used for the test was ASTM 152-H. Atterberg limits test was performed to determine the liquid limit, plastic limit of the Soil A and B. The tests were performed for both the original and polymer stabilized soil with $2,3,4$, and $5 \%$ polymer by weight of dry soil. The ASTM D-4318 [18] was followed to perform these tests.

Linear shrinkage test was performed by using a fabricated mold with $139.7 \mathrm{~mm}$ in length, $25.4 \mathrm{~mm}$ in diameter and $12.7 \mathrm{~mm}$ in depth. The mold was made in Civil Engineering Laboratory at Southern Illinois University Carbondale, Carbondale, IL, USA. The linear shrinkage can be calculated by using the following equation.

Table 1 Properties of polymer

\begin{tabular}{ll}
\hline Property & Characteristics/value \\
\hline Physical state & Milky liquid \\
Odor & Slight \\
Boiling point & $>200{ }^{\circ} \mathrm{F}$ \\
Melting point & $32^{\circ} \mathrm{F}$ \\
Flash point & $>200{ }^{\circ} \mathrm{F}$ \\
Polymer design & $100 \%$ pure acrylic \\
Solubility in water & Dilutable \\
pH & $9.0-9.5$ \\
Total Solids, \% by weight & $59-61$ \\
Density & $1.066 \mathrm{~g} / \mathrm{cm}^{3}$ \\
Particle size & $0.35 \mu \mathrm{m}$ \\
Viscosity, Brookfield & $100-1000 \mathrm{cP}$ \\
Minimum film forming temperature & $8{ }^{\circ} \mathrm{C}$ \\
\hline
\end{tabular}


$\operatorname{LS}(\%)=\frac{L_{s}}{L} \times 100 \%$

where, LS $=$ Linear shrinkage in percent, $L_{s}=$ Linear shrinkage length after oven dried, $L=$ Length of the mold.

\section{Engineering Properties Test}

The standard Proctor test of the original soil samples and soil sample mixed with various percentages of polymer was performed as per ASTM D 698 [19] standard.

The unconfined compression strength (UCS) of the original soil samples and stabilized soil samples was determined as per ASTM 2166/D2166 M [20] standard. The soil samples were prepared at OMC and its maximum dry unit weight obtained from standard Proctor test. However, samples for Soil A mixed with polymer and cured in open air environment were prepared at moisture content and dry unit weight of $12.5 \%$ and $14.92 \mathrm{kN} / \mathrm{m}^{3}$. Soil samples were cured in confined environment as well as open air environment for a period of 7,14 , and 28 days.

To prepare the UCS test samples, oven dried soil sample was mixed with the calculated amount of water. For the soil samples with polymer, the calculated amount of polymer was first mixed with the water and the solution was mixed with the soil. The mixture was mixed thoroughly with hand until the color becomes uniform. The soil sample was compacted in 5 layers in the mold using a hand rammer with approximate weight of $12.0 \mathrm{~N}$. The height to diameter ratio of the prepared sample was maintained approximately two. Since the samples were compacted with hand, the mass of each layer and the height was monitored in order to ensure uniform compaction effort. Before placing the next layer, the top of the placed soil layer was scratched to ensure proper bonding. The soil sample was extruded using the sample extruder and the samples were kept inside zip-lock bags for curing in confined environment and were kept for curing in open air environment as shown in Figs. 1 and 2, respectively. The temperature and the relative humidity of the room were approximately $25 \pm 3{ }^{\circ} \mathrm{C}$ and $29 \pm 2 \%$, respectively. For

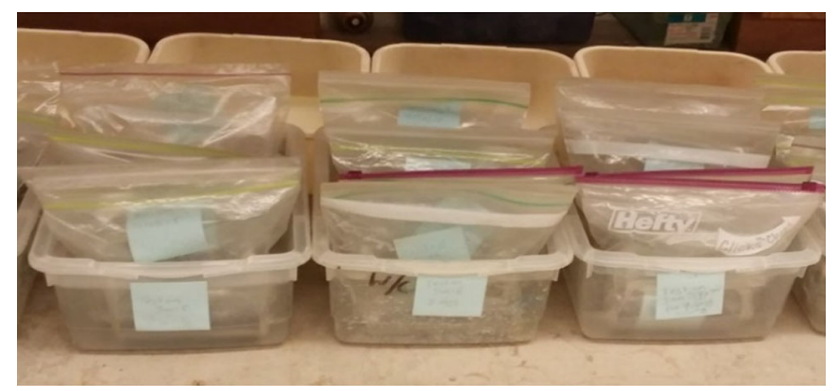

Fig. 1 UCS samples for curing in confined environment

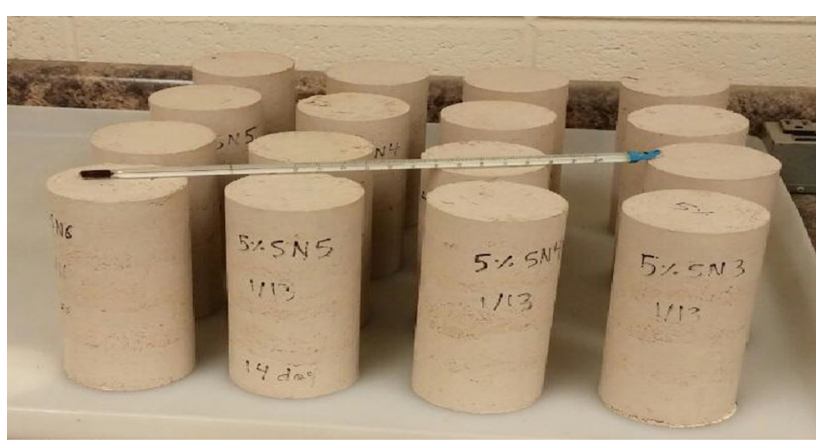

Fig. 2 UCS samples for curing in open air environment

each percentage of polymers, 2 to 3 samples were prepared and the average UCS value was calculated.

For the Soil A samples mixed with polymer, to be cured in open air environment were prepared at dry unit weight of $14.92 \mathrm{kN} / \mathrm{m}^{3}$ and moisture content of $12.5 \%$, because the samples prepared at OMC (optimum moisture content) and MDU (maximum dry unit weight) for Soil A showed crack while curing in open air environment. Open air cured samples were prepared for different moisture content (i.e., $10.0,12.5,15.0$, and $23.5 \%$ ) and the sample prepared at $12.5 \%$ moisture content did not show any visible cracks. So the samples were prepared at this moisture content and tested after 7 days. Humboldt Master loader HM-3000 was used to perform the UCS test. The sample was loaded at a rate of strain $1.27 \mathrm{~mm} / \mathrm{min}$.

California bearing ratio (CBR) of the original soil sample and the polymer stabilized soil sample was performed as per ASTM D 1883 [21] standard. Certain polymer dosages were selected to perform CBR test based on the result of UCS test. CBR test was conducted for 2, 3, and $4 \%$ polymer content for Soil A. Since there was no significant improvement in CBR values after 7 days, it was decided not to perform the CBR test for Soil A for 14, and 28 days curing period. For Soil B sample, CBR test was performed for $4 \%$ polymer content with curing period of 7,14 , and 28 days.

\section{Results and Discussions}

\section{Physical Properties Test}

Specific gravity test of the original Soil A and B was performed using gas pycnometer. The specific gravity of the Soil A and B was 2.57 and 2.61, respectively.

Hydrometer analysis was performed to determine the particle size distribution for both the Soil A and B. The result of hydrometer analysis for Soil A is presented in the Fig. 3. From the Fig. 4, it can be seen that the clay fraction (particle size $<0.002 \mathrm{~mm}$ ) for Soil $\mathrm{A}$ is $42 \%$ and the 
remaining $58 \%$ silt fraction (particle size 0.075-0.002 mm). The result of hydrometer analysis for Soil B is shown in Fig. 3. From the Fig. 5, it can be seen that the clay fraction (particle size $<0.002 \mathrm{~mm}$ ) for Soil B is $73 \%$ and the remaining $27 \%$ silt fraction (particle size 0.075-0.002 mm). According to Unified Soil Classification System (USCS), Soil A is classified as clay with high plasticity (i.e., $\mathrm{CH}$ ) and Soil B is classified as silt with high plasticity (i.e., $\mathrm{MH}$ ).

Liquid limit and plastic limit test was performed for original Soil A and B. The liquid limit for Soil A and B was found to be 61 and 65 , respectively. The plastic limit for Soil A and B was found to be 21 and 35, respectively.

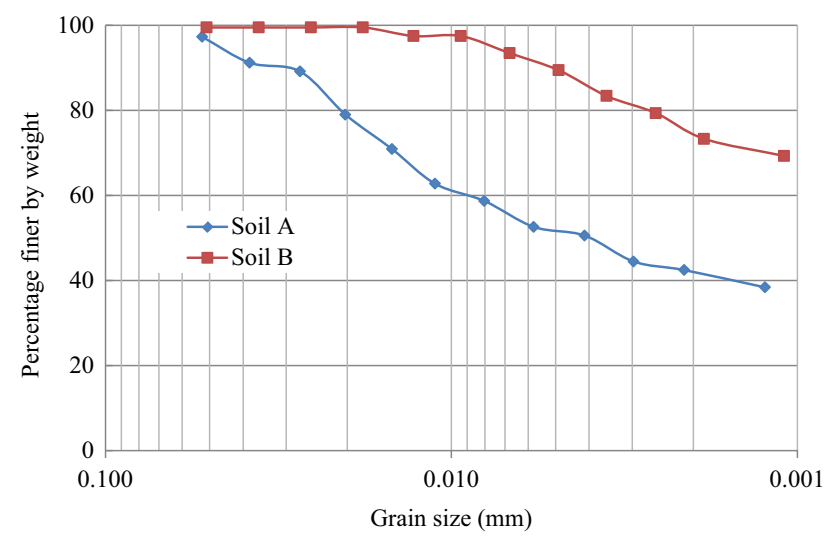

Fig. 3 Hydrometer analysis for Soil A and B
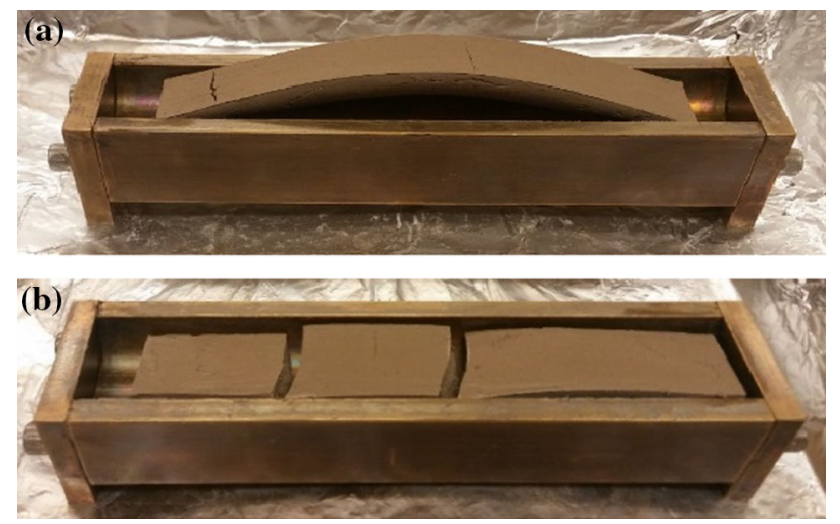

Fig. 4 a Bowing effect in Soil A, b cracking of Soil A sample

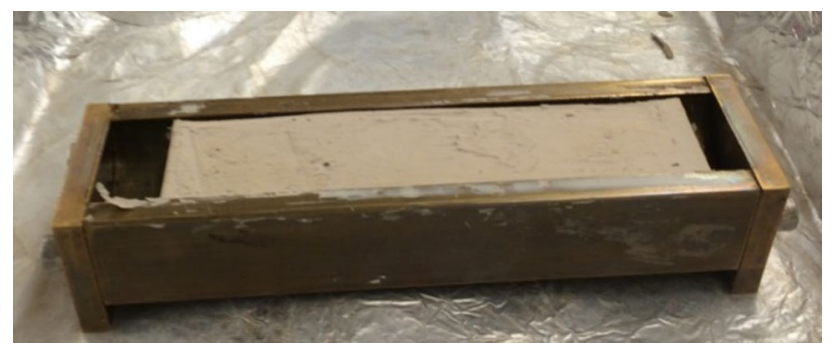

Fig. 5 Shrinked Soil B sample
Liquid limit and plastic limit test was performed for Soil A with different percentage of polymer and the results are presented in Table 2. From Table 2, it can be observed that there was no significant change in the liquid limit and plastic limit value of Soil A with the addition of polymer. Onyejekwe and Ghataora [5] also found no significant change in liquid limit, plastic limit and linear shrinkage with the addition of polymer. Liquid limit and Plastic limit test was performed for Soil B mixed with different percentage of polymer and the results are also presented in Table 2. From the Table 2, it can be noticed that there was no significant effect in the liquid limit and plastic limit with the addition of polymer.

Linear shrinkage test was performed for original Soil A and B. The value of linear shrinkage for Soil A and B was found to be 13 and $15 \%$, respectively. Linear shrinkage test was performed for Soil A mixed with different percentage of polymer and the results are presented in Table 3. From the Table 3, it can be observed that there was marginal change in the linear shrinkage value with the increasing polymer percentage. Bowing effect was seen in Soil $\mathrm{A}$ as shown in Fig. $4 \mathrm{a}$ and some samples cracked in pieces as shown in Fig. 4b. Linear shrinkage test was performed for Soil B mixed with different percentage of polymer and the results are presented in Table 3. From the Table 4, it can be noticed that there was no change in value of linear shrinkage with increasing polymer percentage. There was no bowing effect observed on Soil B and the sample shrinked as an intact or whole unit as shown in Fig. 5.

\section{Engineering Properties Test}

Standard Proctor test was performed for original Soil A and B. The optimum moisture content for Soil A was determined to be $23.5 \%$ and maximum dry unit weight was found to be $15.0 \mathrm{kN} / \mathrm{m}^{3}$. The optimum moisture content for Soil B was found to be $32.4 \%$ and maximum dry unit weight was found to be $13.12 \mathrm{kN} / \mathrm{m}^{3}$. Standard Proctor test was performed for Soil A mixed with different percentage of polymer and the plot of dry unit weight and moisture content for Soil A is shown in Fig. 6. From Fig. 6 it can be noticed that, there was decrease in maximum dry unit weight with the increase in polymer percentage. This is because of the addition of the materials with specific gravities (water and polymer) that are in the range between 1.0 and 1.10. Standard Proctor test was performed for Soil $B$ mixed with different percentage of polymer and the results are presented in Fig. 7. From Fig. 7, it can be seen that for Soil B the maximum dry unit weight decreased with the addition of polymer.

The change in maximum dry unit weight (MDU) and optimum moisture content (OMC) is plotted as a function 
Table 2 Liquid limit and plastic limit test for Soil A and B

\begin{tabular}{|c|c|c|c|c|c|c|}
\hline \multirow[t]{2}{*}{ Polymer (\%) } & \multicolumn{3}{|l|}{ Soil A } & \multicolumn{3}{|l|}{ Soil B } \\
\hline & Liquid limit & Plastic limit & Plasticity index & Liquid limit & Plastic limit & Plasticity index \\
\hline 0 & 61 & 21 & 40 & 66 & 36 & 30 \\
\hline 2 & 61 & 23 & 38 & 65 & 35 & 30 \\
\hline 3 & 61 & 23 & 38 & 65 & 33 & 32 \\
\hline 4 & 58 & 21 & 37 & 65 & 33 & 32 \\
\hline 5 & 60 & 21 & 39 & 66 & 35 & 31 \\
\hline
\end{tabular}

Table 3 Linear shrinkage value for Soil A and B

\begin{tabular}{lll}
\hline Polymer (\%) & \multicolumn{2}{l}{ Linear shrinkage (\%) } \\
\cline { 2 - 3 } \cline { 2 - 3 } & Soil A & Soil B \\
\hline 0 & 14 & 15 \\
2 & 14 & 15 \\
3 & 14 & 15 \\
4 & 16 & 15 \\
5 & 15 & 15 \\
\hline
\end{tabular}

Table 4 CBR value for Soil A with varying polymer percentage

\begin{tabular}{ll}
\hline Polymer (\%) & CBR (\%) \\
\hline 0 & 10.57 \\
2 & 11.27 \\
3 & 12.07 \\
4 & 11.87 \\
\hline
\end{tabular}

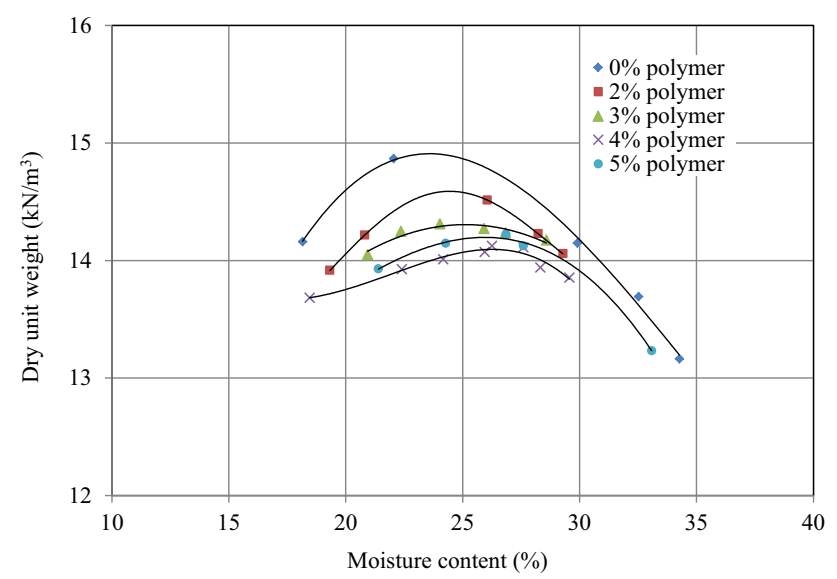

Fig. 6 Standard proctor test result for Soil A

of polymer addition rate. The graph of this change for Soil A and B is shown in Figs. 8 and 9, respectively.

Unconfined compression strength (UCS) test was performed for Soil A and Soil B mixed with $0,2,3,4$, and $5 \%$

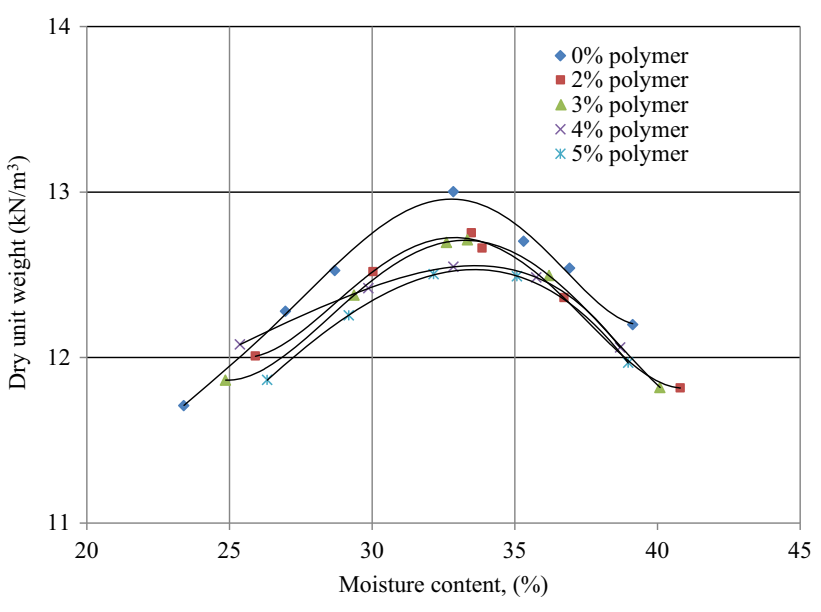

Fig. 7 Standard proctor test result for Soil B

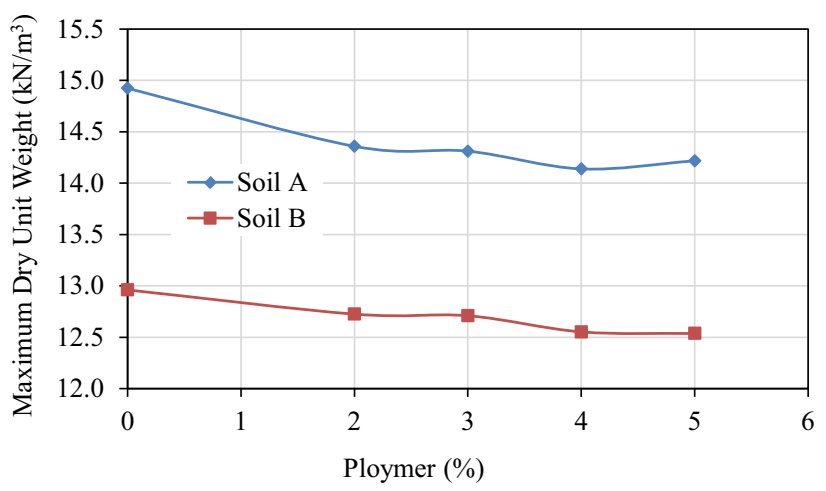

Fig. 8 Maximum dry unit weight vs polymer percentage

of polymer. The cylindrical soil samples (diameter $=72$ $0.5 \mathrm{~mm}$ and height $=145.0 \mathrm{~mm}$ ) prepared at optimum moisture content and its maximum dry unit weight were cured in confined environment and open air environment. The cylindrical samples were tested after a curing period of 7, 14, and 28 days. The UCS strength vs polymer percentage for Soil A cured in confined environment for 7, 14, and 28 days is shown in Figs. 10, 11 and 12, respectively. It was observed that the UCS strength varies from $(-10$ to $+13 \%$ ) with the addition of polymer for Soil A samples 


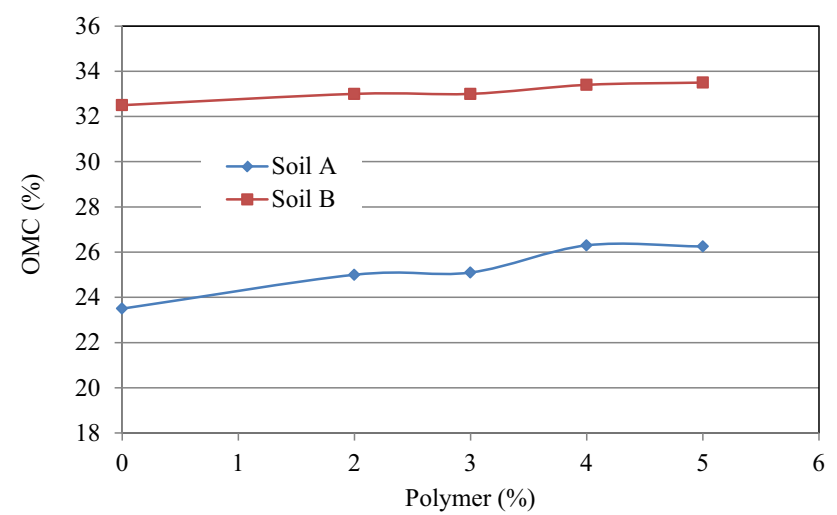

Fig. 9 Optimum moisture content vs polymer percentage

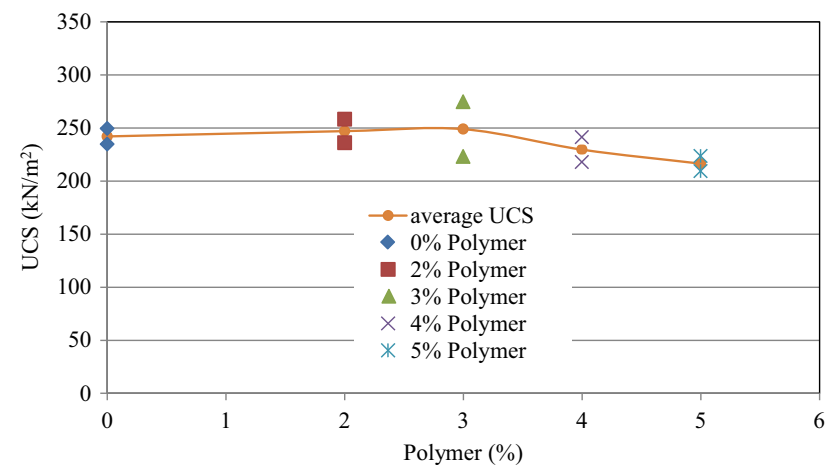

Fig. 10 UCS test result for Soil A + polymer cured in confined environment (7 days)

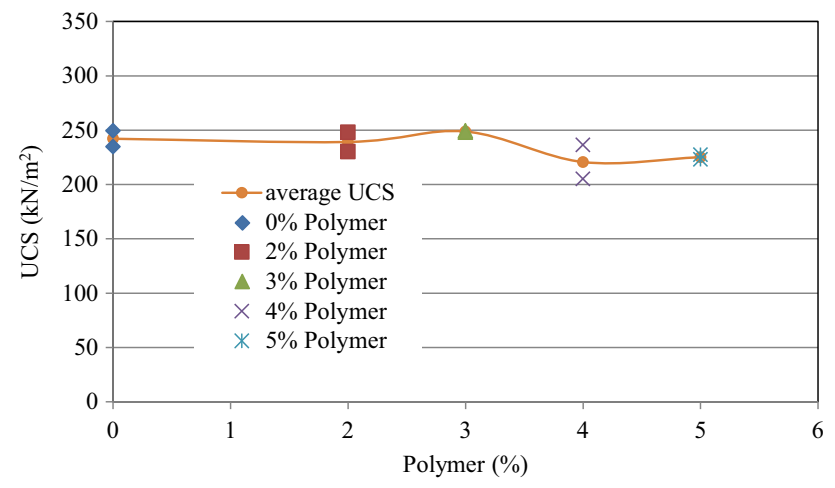

Fig. 11 UCS test result for Soil A + polymer cured in confined environment (14 days)

cured in confined environment. In confined environment, the moisture could not evaporate as a result polymerization could not occur and there was no significant gain in strength. For the polymer stabilized soil to gain strength the entrapped water should evaporate, since the water was not allowed to escape in confined environment it hindered the bonding process and there was no increase in UCS strength. Similar result was obtained by Geiman et al. [22] for the polymer treated soil in confined curing

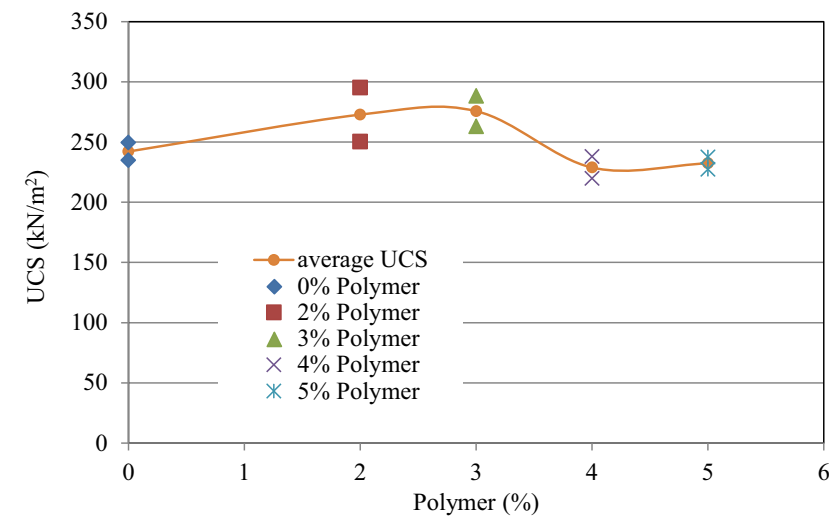

Fig. 12 UCS test result for Soil A + polymer cured in confined environment (28 days)

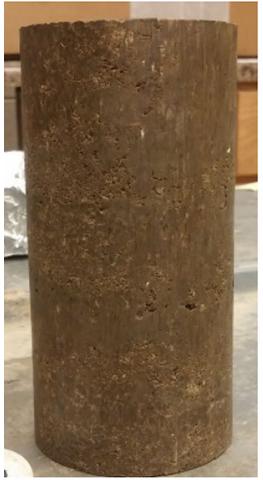

Day 1

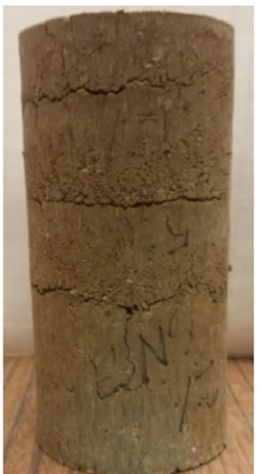

Day 2

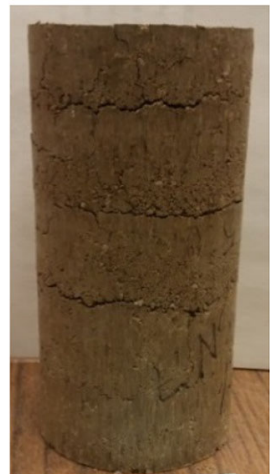

Day 3
Fig. 13 Soil A samples cured in open air environment

environment. So the curing environment has major influence on the performance of the polymer stabilized soil.

Since there was no significant gain in strength in confined environment, samples for Soil A were cured in open air environment. The samples were prepared at optimum moisture content and maximum dry unit weight and cured in open-air environment at a temperature of $25 \pm 3{ }^{\circ} \mathrm{C}$ and relative humidity of $29 \pm 2 \%$. However, due to cracking as shown in Fig. 13, the UCS test could not be performed for the Soil A samples prepared at OMC and MDU, and cured in open air environment.

Hence, the UCS samples were prepared at lower moisture content and a fixed dry unit weight to reduce cracking due to moisture loss. For Soil A, the samples were prepared at a moisture content of $12.5 \%$ and dry unit weight of $15.0 \mathrm{kN} / \mathrm{m}^{3}$. The UCS samples prepared at this moisture content did not show any cracking and were tested. The result for Soil A cured in open-air environment for 7 days is shown in Fig. 14. It was observed that there was a marginal increase in strength with the addition of polymer. The maximum increase in strength observed is 10.7 for 
$4 \%$ polymer content. The polymer works by coating the soil particle, and for layered structure the polymer could not sufficiently coat the soil particles resulting in marginal increase in UCS strength with the addition of polymer.

There was no increase in strength for Soil A in confined environment. For Soil B, samples were prepared at $2 \%$ Polymer content and cured in confined environment for 14 and 28 days. The plot for UCS value vs curing period in days is shown Fig. 15. It can be seen from Fig. 15 that, in confined environment there is an increase of $12-14 \%$ in UCS strength with the addition of polymer with curing periods. In the confined environment the entrapped moisture could not evaporate from the sample, as a result there was no significant strength gain. The difference in UCS strength may be due to the differences in compaction effort during sample preparation. Since the samples were compacted manually, it was difficult to maintain the uniform compaction effort each time while preparation of the samples.

For Soil B mixed with polymer the samples were prepared at optimum moisture content and its corresponding maximum dry unit weight and left to cure in open air

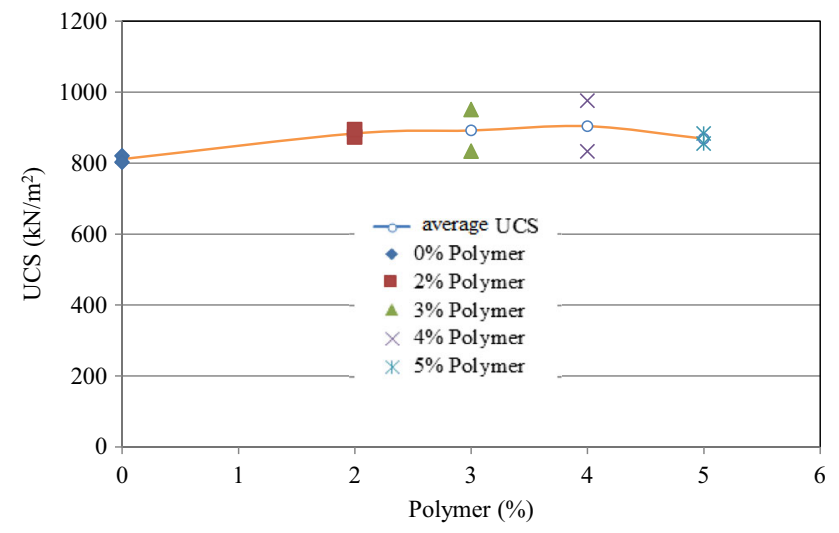

Fig. 14 UCS test result for Soil A + polymer cured in open air environment ( 7 days)

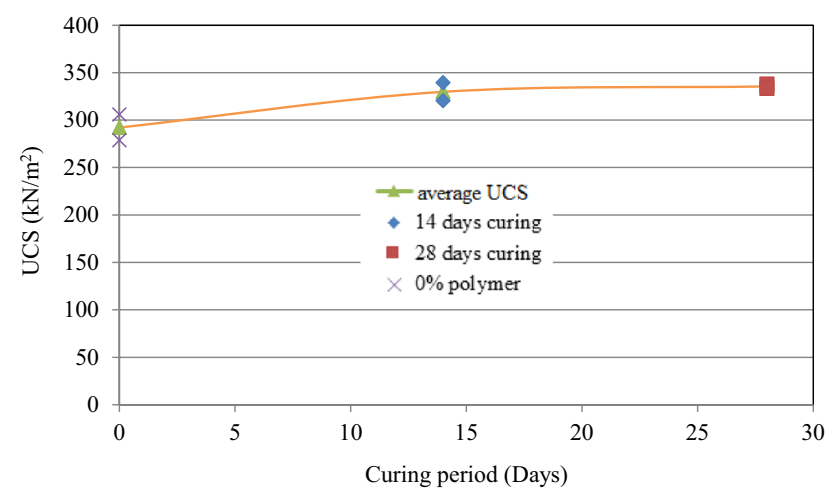

Fig. 15 UCS test result for Soil B $+2 \%$ polymer cured in confined environment environment in the room at a temperature of an approximately $25 \pm 3{ }^{\circ} \mathrm{C}$ and relative humidity of $29 \pm 2 \%$. For Soil $\mathrm{B}$, no cracks were observed while curing in open-air environment.

The UCS value of open air cured original Soil B and Soil A is 2225.30 and $811.33 \mathrm{kN} / \mathrm{m}^{2}$, respectively. The dry unit weight of Soil B sample was $12.96 \mathrm{kN} / \mathrm{m}^{3}$ before curing in open air environment. After curing for 7 days, the dimension of sample decreased (i.e., $5.2 \%$ in length and $3.5 \%$ in diameter) and the dry unit weight increased to $14.53 \mathrm{kN} / \mathrm{m}^{3}$. Also at the time of testing, the moisture content of Soil B decreased to 1.5-2.0 \% from 32.5\% (i.e., OMC) at the time of sample preparation. This lower moisture content and increase in dry unit weight could be the reason for higher UCS value observed in original Soil B cured in open air environment.

The UCS test result for Soil B mixed with different percentage of polymer and cured for 7,14 and 28 days in open air environment is shown in Figs. 16, 17 and 18, respectively. From Figs. 16, 17 and 18, it can be noticed that there is a significant increase in strength with the addition of polymer for Soil B cured in open air environment. The maximum increase in strength is $75.5 \%$ for sample with $4 \%$ polymer content cured for 28 days. The strength gains for 14 days' open air cured sample is close to that of 28 days; so this polymer can be useful in situations where rapid gain in strength is needed. Azzam [14] also found that UCS value increased rapidly for first 7 days and was almost constant after that. Tingle and Santoni [23] also obtained variable improvement in dry UCS strength of polymer stabilized soil. Marto et al. [24] also found improvement in UCS value of clayey soil with the addition of polymer. Zandieh and Yasrobi [9] also found significant improvement in compressive strength with the addition of polymer on sandy soil. Al-Khanbashi and Abdalla [2] also found increase in compressive strength of sandy soil with the addition of polymer.

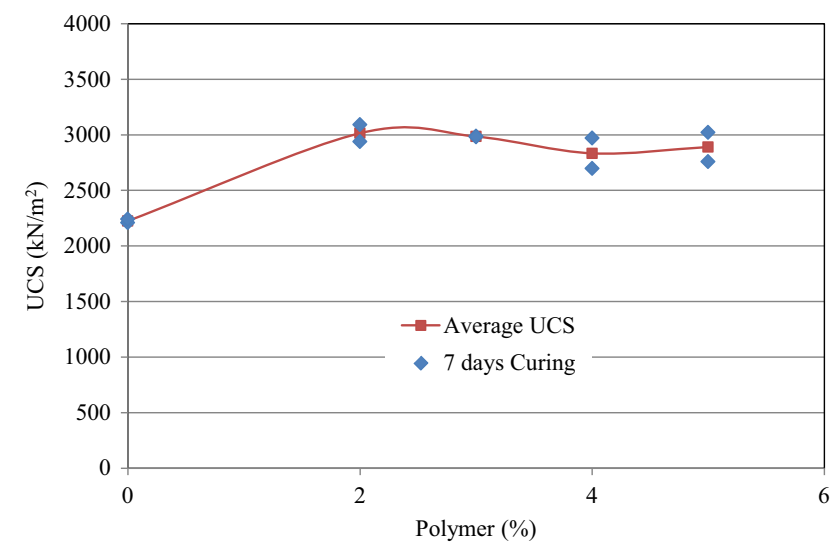

Fig. 16 UCS test result for Soil B + polymer cured in open air environment (7 days) 
California bearing ratio test was performed for original Soil A and Soil A mixed with 2, 3, and $4 \%$ polymer content cured for 7 days and the results are presented in Table 4. CBR test was performed for original Soil B and Soil B mixed with $4 \%$ polymer cured for 7,14 , and 28 days. The samples for CBR test were prepared at optimum moisture content and its maximum dry unit weight for both soil samples. The CBR value for original Soil B and Soil B mixed with $4 \%$ polymer and cured for 7,14 , and 28 days is shown in Table 5. The CBR value for original Soil B is $8.67 \%$. There was significant increase in CBR value with the addition of polymer for Soil B. Mousavi et al. [15] found an increase in CBR value with the addition of polymer for clayey soil. Kavak et al. [25]

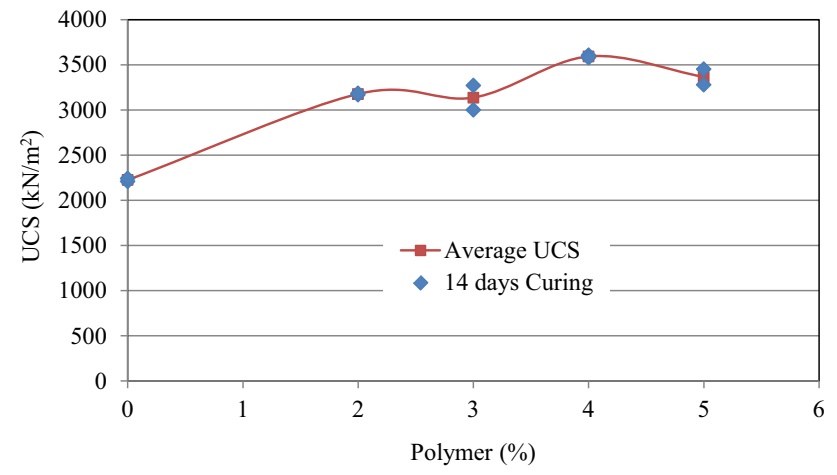

Fig. 17 UCS test result for Soil B + polymer cured in open air environment (14 days)

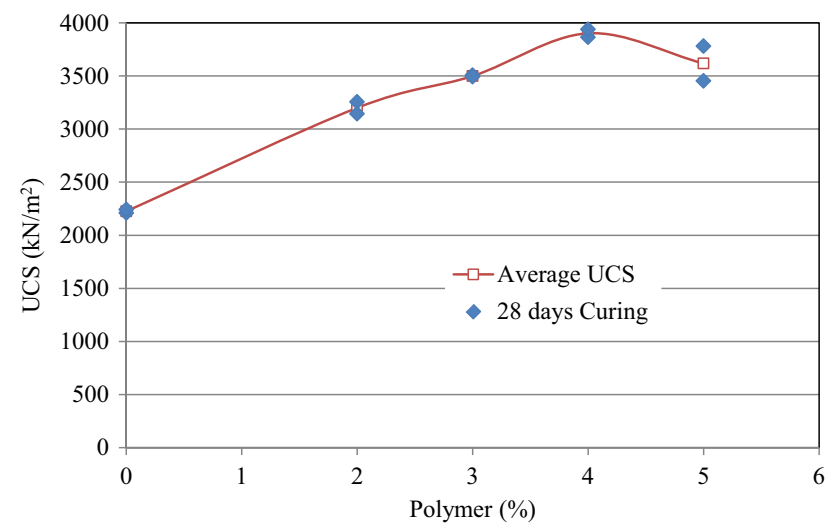

Fig. 18 UCS test result for Soil B + polymer cured in open air environment ( 28 days)

Table 5 CBR value for Soil B mixed with $4 \%$ polymer cured for 7,14 , and 28 days

\begin{tabular}{lc}
\hline Curing time (days) & CBR (\%) \\
\hline 0 & 8.67 \\
7 & 18.73 \\
14 & 20.70 \\
28 & 38.27 \\
\hline
\end{tabular}

also found an increase in CBR value of base material for road construction with the addition of polymer.

\section{Conclusions}

The main purpose of this paper was to study the effect of liquid polymer on the physical and geotechnical properties of fine-grained soil. The following conclusions can be drawn based on the experimental study performed.

- The liquid limit and plastic limit of Soil A sample were found to be 61 and 21 , respectively. The liquid limit and plastic limit of Soil B were found to be 66 and 36, respectively. There was no significant change in the Atterberg limits of both the soil sample (i.e., Soil A and B) with the addition of polymer.

- The linear shrinkage value for Soil A and B was found to be 13 and $15 \%$, respectively. Marginal to no change was observed in the value of linear shrinkage with the addition of polymer for both the soil types.

- Standard Proctor test was performed on both soils and was found that the MDU for Soil A and B were 14.92 and $12.96 \mathrm{kN} / \mathrm{m}^{3}$, respectively. The OMC for Soil A and $\mathrm{B}$ were 23.5 and $32.5 \%$, respectively. With the addition of polymer there was a decrease (i.e., 1.8-5.2\%) in dry unit weight however, there was change (i.e., 1.5-11.9\%) in optimum moisture content for both the soil (i.e., Soil A and B) types.

- Unconfined compression test was performed for both the original soil samples and soil samples mixed with polymer. There was no significant increase in UCS strength of the Soil A and B cured in confined environment. Also, for Soil A sample cured in open air environment there was very marginal increase (i.e., 7-10\%) in strength with the addition of polymer. There was significant increase (i.e., 30-75\%) in UCS strength of the Soil B sample cured in open air environment with the addition of polymer. It was observed that the strength of the samples cured in open air environment after 14 days does not increase much. Due to the fluctuation in temperature and humidity of the room used for sample curing, there was some variation in the result of UCS strength for open air cured samples. Similar results were observed by Tingle and Santoni [23].

- CBR test was performed for original Soil A sample and soil sample mixed with 2,3 , and $4 \%$ polymer content cured for 7 days. Marginal increase (i.e., 6.6-14.1\%) in strength was observed for polymer treated Soil A. CBR test was also performed for original and Soil B mixed with $4 \%$ polymer and cured for 7,14 , and 28 days. The results show that the CBR value for Soil B 
mixed with polymer was $340 \%$ higher than that of the original soil sample. Also, there was increase in CBR value with the curing time.

\section{References}

1. Patel MA, Patel HS (2012) A review on effects of stabilizing agents for stabilization of weak soil. Civil Environ Res 2(6):1-7

2. Al-Khanbashi A, Abdalla SW (2006) Evaluation of three waterborne polymers as stabilizers for sandy soil. Geotech Geol Eng 24(6):1603-1625

3. Georgees RN, Hassan RA, Evans RP, Jegatheesan P (2015) Effect of the use of a polymeric stabilizing additive on unconfined compressive strength of soils. Trans Res Rec: J Trans Res Board 2473:200-208

4. Tingle J, Newman J, Larson S, Weiss C, Rushing J (2007) Stabilization mechanisms of nontraditional additives. Transp Res Rec 1989 1:59-67

5. Onyejekwe S, Ghataora GS (2015) Soil stabilization using proprietary liquid chemical stabilizers: sulphonated oil and a polymer. Bull Eng Geol Environ 74(2):651-665

6. Leon LR, Matthews C (2003) Storm water quality handbooks: construction site best management practices (BMPs) manual

7. Rauch A, Harmon J, Katz L, Liljestrand H (2002) Measured effects of liquid soil stabilizers on engineering properties of clay. Transp Res Rec 1787(1):33-41

8. Newman K, Tingle JS (2004) Emulsion polymers for soil stabilization. In: FAA worldwide airport technology transfer conference, April 2004. Atlantic City, New Jersey

9. Zandieh AR, Yasrobi SS (2010) Study of factors affecting the compressive strength of sandy soil stabilized with polymer. Geotech Geol Eng 28(2):139-145

10. Tang C, Shi B, Liu C, Gao L, Inyang HI (2011) Experimental investigation of the desiccation cracking behavior of soil layers during drying. J Mater Civ Eng 23(6):873-878

11. Naeini SA, Naderinia B, Izadi E (2012) Unconfined compressive strength of clayey soils stabilized with waterborne polymer. KSCE J Civ Eng 16(6):943-949
12. Iyengar SR, Masad E, Rodriguez AK, Bazzi HS, Little D, Hanley HJM (2013) Pavement subgrade stabilization using polymers: characterization and performance. J Mater Civ Eng 25(4):472-483

13. Azzam WR (2014) Behavior of modified clay microstructure using polymer nanocomposites technique. Alex Eng $\mathrm{J}$ 53(1): $143-150$

14. Azzam WR (2014) Durability of expansive soil using advanced nanocomposite stabilization. Int J GEOMATE 7(1):927-937

15. Mousavi F, Abdi E, Rahimi H (2014) Effect of polymer stabilizer on swelling potential and CBR of forest road material. KSCE J Civ Eng 18(7):2064-2071

16. ASTM D 5550-00 (1996) Standard test method for specific gravity of soil solids by gas pycnometer. ASTM International, West Conshohocken

17. ASTM D 422-63 (1998) Standard test method for particle-size analysis of soils. pp 1-8

18. ASTM D 4318 (2010) Standard test methods for liquid limit, plastic limit, and plasticity index of soils. pp 1-14

19. ASTM D 698 (2011) Standard test methods for laboratory compaction characteristics of soil using standard effort. ASTM International, West Conshohocken

20. ASTM D 2166/D 2166M (2013) Standard test method for unconfined compressive strength of cohesive soil. ASTM International, West Conshohocken

21. ASTM D 1883 (2014) Standard test method for California bearing ratio (CBR) of laboratory-compacted soils. ASTM International, West Conshohocken

22. Geiman CM, Filz G, Brandon TL (2005) Final contract report stabilization of soft clay subgrades in Virginia: Phase I Laboratory Study, Department of Civil and Environmental Engineering, Virginia Tech, USA, Report no. VTRC 05-CR16

23. Tingle J, Santoni R (2003) Stabilization of clay soils with nontraditional additives. Trans Res Rec: J Trans Res Board 1819:72-84

24. Marto A, Latifi N, Sohaei H (2013) Stabilization of laterite soil using GKS soil stabilizer. Electron J Geotech Eng 18:521-532

25. Kavak A, Bilgen G, Mutman U (2010) In-situ modification of a road material using a special polymer. Sci Res Essays 5(7):2547-2555 